\title{
ENTRE O CONCEITO DE CRÍTICA DE ARTE E A ARTE DA CRÍTICA
}

OLIVEIRA, Bernardo Barros Coelho de. Olhar e narrativa: leituras benjaminianas. Vitória: Edufes, 2006.

\author{
Patrick E. C. Pessoa* \\ patrickpessoa@gmail.com
}

Desde 1997, quando concluiu o seu doutorado em filosofia sobre a terceira crítica de Kant, Bernardo Oliveira, professor da Universidade Federal do Espírito Santo, vem concentrando os seus esforços na leitura da obra de Walter Benjamin, sobre a qual versa a maioria dos ensaios por ele produzidos entre 1998 e 2005 . Relidos e revisados, nove desses ensaios compõem Olhar e narrativa: leituras benjaminianas. Embora eles sejam autônomos e a princípio possam ser lidos independentemente uns dos outros, fica evidente para o leitor que acaba de percorrer o livro que esses nove ensaios foram organizados de modo a formar uma constelação em que cada texto, iluminando os demais e deixando-se por eles iluminar, ajuda a tornar visível uma imagem bastante pessoal da obra de Walter Benjamin. Essa imagem, adverte o autor já no prefácio, "se parece com uma intrincada paisagem urbana" e "pode não agradar àqueles que esperam um desenho de perspectiva clássica, no qual tudo converge para o mesmo ponto" (p. 8).

A diferença entre um desenho de perspectiva clássica e uma paisagem urbana é análoga à diferença entre a tendência dos grandes sistemas filosóficos

* Professor da Universidade Gama Filho e do Colégio São Vicente de Paulo, Rio de J aneiro, Brasil. 
de explicar univocamente o sentido de um fenômeno e a proposta benjaminiana de simplesmente mostrar o fenômeno, religando todas as coisas díspares que o compõem sem com isso anular ou recalcar a sua disparidade. Se nos recordarmos que o inacabado Trabalho das passagens, obra que ocupou o cerne da reflexão de Benjamin em sua maturidade, é a apresentação filosófica exemplar do que seja uma intrincada paisagem urbana, tornar-se-á claro que, para Bernardo Oliveira, trata-se menos de reconstruir os passos da obra do filósofo alemão - "suas propostas teóricas específicas, certos conceitos e suas definições, certos diagnósticos e/ou previsões" (p. 58) - do que de privilegiar o seu gesto - "o incansável esforço de ler, com igual atenção, fenômenos os mais diversos, ver neles correspondências decisivas, analogias, semelhanças, tanto entre fenômenos altamente letrados da cultura dita 'alta' (termo hoje fora de moda) quanto entre os de quaisquer outras modalidades culturais: moda, publicidade, arquitetura comercial, processos industriais. Para Walter Benjamin, tudo era texto" (p. 57).

Ainda que, evidentemente, não se possa interpor uma fronteira rígida entre o gesto de um filósofo e os passos de sua obra, a maior virtude do livro de Bernardo Oliveira é a sua preocupação em reconstruir os passos da obra benjaminiana apenas na medida em que estes servem para iluminar o seu gesto, apenas na medida em que podemos aprender com ele. Se essa preocupação transparece já na organização e na escritura do livro, em que saltam à vista estratégias de construção textual semelhantes às empregadas por Walter Benjamin, como a montagem literária e a repetição de citações em textos e contextos diversos, ela encontra a sua principal legitimação no terceiro e último capítulo do livro, dedicado à interpretação de obras de autores contemporâneos. Esse capítulo, o mais original e corajoso do livro, revela que Bernardo Oliveira logrou incorporar o gesto benjaminiano, transformando sangue alheio em próprio. Como, entretanto, segundo o próprio autor, é "sempre mais fértil indagar o que uma obra quer do que aferir de modo arrogante o que ela de fato consegue" (p. 40), voltemos agora a nossa atenção para o modo como o livro Olhar e narrativa: leituras benjaminianas foi estruturado.

Três são os temas que, segundo o autor, serviram de fio condutor à reunião dos nove ensaios por ele coligidos: "a relação do crítico Walter Benjamin com as obras que escolheu criticar, a historicidade da percepção e sua particular relação com a obra de arte, e, por fim, a influência destas formas históricas na narrativa, fenômeno cultural emblemático do que chamamos de memória" ( $p$. 9). Cada um dos três capítulos da obra é estruturado em torno de um desses três temas, os quais, por sua vez, remontam aos vários níveis de "leituras benjaminianas" entretecidos no livro de Bernardo Oliveira. 
Em seu primeiro nível, a leitura empreendida pelo autor é benjaminiana porque os textos do próprio Walter Benjamin, especialmente aqueles em que se discute explicitamente o conceito de crítica de arte, são o objeto de investigação e servem à definição do que seria propriamente ler com(o) Benjamin. Ao longo dos três ensaios que compõem o primeiro capítulo do livro, o autor mostra de que modo Benjamin se apropriou do conceito de crítica de arte do primeiro romantismo alemão, tema de sua tese de doutorado, concluída em 1919. A partir da citação de diversas passagens tomadas de empréstimo por Benjamin a Friedrich Schlegel e Novalis, Bernardo Oliveira reconstrói a compreensão benjaminiana da crítica de arte, segundo a qual o leitor, pensado como "o autor ampliado" (p. 17), é ainda mais responsável pela potência de significar da obra do que aquele que a assina. A tarefa do crítico, sob essa ótica, não seria a de realizar um juízo sobre a obra, o qual pressupõe que a obra já esteja acabada, mas sim a de fornecer o "método para o seu acabamento" (p. 15). O método para esse inacabável acabamento da obra, por sua vez, nada teria de arbitrário. Cumpriria ao crítico deixar-se orientar pela obra que se propõe a analisar, desdobrando o germe crítico que estaria presente em todas as obras de arte efetivamente criticáveis, aquelas que os românticos chamavam de irônicas. Ao desenvolver a auto-reflexividade imanente à obra a partir dos elementos presentes em sua própria situação histórica, aí naturalmente incluídas as leituras anteriores da obra criticada, cada novo crítico acabaria por descobrir novas correspondências entre o texto da obra e o texto do mundo, entre a obra como fragmento de uma história que a ultrapassa e o mundo como uma constelação de elementos díspares que não raro só se tornam visíveis (e significativos) a partir da obra. Essa concepção da tarefa do crítico de arte, como a tarefa de contribuir para a intensificação da potência de significar da obra analisada, seria, segundo Bernardo Oliveira, a radicalização daquela idéia kantiana de que uma obra de arte bela "dá muito o que pensar, sem que contudo qualquer pensamento determinado (...) possa ser-lhe adequado" (p. 15). Ao deslocar o crítico daqueles papéis tradicionais de juiz da arte ou de perquiridor imparcial do sentido da obra, em geral concebido como simplesmente dado, independente do trabalho da crítica e associado às intenções do artista, os românticos teriam inaugurado uma estética da recepção em sentido forte. No âmbito dessa estética, em que a obra é pensada como medium-de-reflexão, o valor da arte depende fundamentalmente de sua capacidade de promover sempre novas leituras, desencadeando uma reflexividade potencialmente infinita. Esse poder da obra de arte de dar o que pensar e assim ocupar o centro de uma rede de linguagem em que múltiplas correspondências hão de surgir, trazendo à luz sentidos insuspeitos, é talvez o que mais atrai o olhar de Bernardo Oliveira 
para o conceito de crítica de arte (no romantismo alemão) como lido por Walter Benjamin. Ao contrário daqueles estetas que, na esteira de Heidegger, combatem a mercantilização da arte propondo a sua reauratização, o autor, ainda que não o afirme explicitamente, aposta na discursividade desauratizante exigida pelas obras de arte como caminho de resistência ao império do sentido e à mobilização total.

Ainda que o primeiro capítulo do livro não tenha como foco único a discussão da leitura benjaminiana do conceito de crítica de arte do primeiro romantismo - o segundo ensaio de Olhar e narrativa, por exemplo, aborda a memória involuntária de Proust para fundamentar a idéia de uma contigüidade não-linear entre a flânerie baudelairiana e o cinema falado -, é apenas no segundo capítulo do livro que se tornará visível de que modo Benjamin, ao intensificar o conceito de crítica de arte de Schlegel e Novalis, diferencia-se deles.

O segundo capítulo de Olhar e narrativa é dedicado aos textos benjaminianos da década de 1930, em que a concepção romântica da obra de arte como medium-de-reflexão, analisada pelo filósofo em sua obra de 1919, ganhará um desdobramento materialista. Composto por dois ensaios, a leitura empreendida nesse capítulo é duplamente benjaminiana, pois o autor apresenta uma leitura inspirada por Benjamin das leituras realizadas por Benjamin daqueles autores de sua predileção, como Baudelaire e Kafka, a partir das quais ele teria derivado a sua teoria da percepção tátil e a sua descrição marcadamente baudelairiana da sensibilidade característica da Modernidade. Seu ponto de partida é a idéia de que a estética, pensada modernamente como a disciplina filosófica que se ocupa do campo das experiências humanas ligadas ao belo (e por extensão às artes), não pode ser dissociada da estética, pensada pelos gregos como uma investigação das sensações, das condições de percepção em geral. Segundo o autor, porém, Benjamin, ao mesmo tempo que propõe a retomada de uma concepção mais abrangente do campo da estética, deixa claro, em um fragmento que é citado diversas vezes ao longo de Olhar e narrativa, que, "no interior de grandes períodos históricos, a forma de percepção das coletividades humanas se transforma ao mesmo tempo que seu modo de existência. O modo pelo qual se organiza a percepção humana, o meio em que ela se dá, não é apenas condicionado natural, mas também historicamente" (p. 32). Mais do que propor uma simples reaproximação entre uma teoria da percepção em geral e uma teoria da percepção do belo nas artes, o propósito de Benjamin é chamar a atenção para o fato de que nenhuma investigação estética do belo nas artes pode prescindir de uma investigação estética das condições materiais específicas que subjazem à produção e à 
recepção das obras de arte em um dado momento da história. Ao defender uma historicização radical da estética, Benjamin será obrigado a retomar em outro registro a concepção de Schlegel, também citada mais de uma vez por Bernardo Oliveira, de que "apenas o incompleto pode ser compreendido, pode nos levar mais além. O completo pode ser apenas desfrutado" (p. 16). Para justificar a sua concepção de que a incompletude - da qual a ironia que critica e exige a crítica seria o vestígio mais eloqüente - é o que diferencia obras de arte de simples mercadorias e artefatos comuns, não lhe bastará simplesmente retomar algumas teses ontológicas do primeiro romantismo, segundo as quais o mundo seria um "livro cifrado" (p. 78) e a natureza um "hieróglifo da divindade" (p. 79) cujo significado se perdeu. Benjamin terá de mostrar por que o mundo moderno, o nosso mundo, do qual provêm essas obras de arte incompletas e fragmentárias que exigem uma leitura potencialmente infinita, é um mundo cifrado, enigmático, fragmentário. Para realizar essa tarefa, considerações ontológicas acerca da finitude do homem e do caráter babélico da linguagem humana, por serem em princípio a-históricas, são insuficientes. Por mais importantes que sejam tais considerações, elas não têm como explicar a especificidade do olhar caracteristicamente moderno e do tipo de narrativa que esse olhar exige ou engendra. Assim, embora Bernardo Oliveira tenha definido o livro de Benjamin sobre o romantismo alemão como a sua "carta de princípios" (p. 13) e "a ética-poética iniciada por autores como Schlegel e Novalis" (p. 77) como a base da ética-poética de autores modernos como Kafka, o segundo capítulo de seu livro será dedicado a analisar os desdobramentos da teoria benjaminiana, assumidamente materialista, de que a origem da sensibilidade moderna e conseqüentemente da arte moderna deve ser reportada ao surgimento das metrópoles modernas. Ao analisar as observações benjaminianas sobre a Paris de Baudelaire, Bernardo Oliveira recorta e monta habilmente uma série de citações tanto de Benjamin quanto de Baudelaire - o célebre poema "A uma passante" é central para a construção do argumento do capítulo como um todo - de modo a revelar que a compreensão da gênese da forma de percepção sensorial que caracteriza a Modernidade depende de que recuperemos o espanto face a uma série de situações que, hoje corriqueiras, decerto foram extraordinárias para os parisienses do século XIX. "Pela primeira vez na história, indivíduos se viam na situação de ficar frente a frente com um desconhecido durante horas, por exemplo, num bonde urbano, sem trocar uma só palavra com ele. (...) No século XIX, um destes passageiros do bonde poderia ter nascido num vilarejo ou numa área rural onde todos sabiam não só a história de seus vizinhos, mas também de boa parte de sua ascendência" (p. 60). Nessa situação inédita e nada acolhedora, origem por 
exemplo do romance policial, em que cada transeunte desconhecido pode estar a caminho de um crime, o sentido privilegiado é o olhar, que não apenas tem de lidar com as potenciais ameaças dos desconhecidos que cruzam o nosso caminho e do tráfego intenso, mas que além disso é constantemente bombardeado por incontáveis estímulos, como o belo porte de uma mulher que acaba de passar - corta - uma propaganda - corta - um modelo de chapéu desconhecido - corta - o letreiro de uma loja etc. A esses instantes perceptivos fugazes e intensos localizados entre dois cortes, Benjamin chamará de choque. Segundo ele, a percepção moderna desenvolve-se como uma defesa contra os choques, e o homem das grandes cidades precisa ser treinado para suportar esses verdadeiros esbarrões visuais - da idéia de um esbarrão, que remete ao sentido do tato, é que o Benjamin de Bernardo Oliveira deriva a expressão "percepção tátil", muito embora a percepção tátil seja eminentemente visual, e assinale o ocaso de uma sensibilidade pré-moderna, em que o olhar aparecia como metáfora da contemplação. A forma de arte que corresponde à percepção moderna como choque, assinala o autor, é o cinema. A questão é que o cinema, desde a sua origem uma expressão artística que oscila entre a resistência e a adesão incondicional ao império da mercadoria, é essencialmente ambíguo no que diz respeito à sua relação com o espectador. Se ele sem dúvida dispõe da capacidade de nos acostumar a experimentar o abrupto, o fragmentário e o efêmero como prazerosos, assim contribuindo para que os modernos possamos superar a nostalgia de um mundo fechado para sempre inacessível, essa capacidade pode ser utilizada de dois modos radicalmente distintos. O primeiro desses modos caracterizaria, segundo a tipologia proposta por Bernardo Oliveira, o cinema como "arte de entretenimento (leia-se, adestramento)" (p. 70), o cinema voltado para o mercado. Os filmes produzidos de acordo com esse modelo, embora apresentem um número de planos e de cortes que beira o vídeo-clipe, e que assim inviabiliza qualquer nível de contemplação, mascaram a sua descontinuidade elementar através de técnicas narrativas que, a um só tempo, encobrem a subjetividade inerente à montagem e integram todos os elementos díspares que constituem o filme em uma história com começo, meio e fim, isto é, com uma moral e uma mensagem que os espectadores são obrigados a engolir sem qualquer reflexão. Nesse cinema, que ironicamente reivindica para si a alcunha de realista e que é aceito como tal pela maior parte do público, o espectador é confortado pela idéia de que o caráter fragmentário da realidade é apenas aparente - os heróis desse tipo de filme sempre acabam por triunfar sobre a desordem do mundo, colocando-o nos eixos - e simultaneamente é treinado para responder com o máximo de eficiência "aos desafios inerentes à produtividade capitalista" (p. 70). O cinema 
como "arte de vanguarda" (p. 70), por outro lado, trabalha sempre a partir da ostentação da descontinuidade elementar que caracteriza a base material do cinema - séries sucessivas de imagens separadas por cortes - e recusa-se a vender a idéia de que haveria um sentido profundo por trás daquelas imagens, simplesmente esperando ser descoberto. O cinema de vanguarda, portanto, ao reproduzir fielmente o caráter "chocante" da nossa percepção cotidiana, nos acostumaria a lidar com a ausência de um sentido profundo que eliminasse a desorientação do homem no mundo moderno, isto é, nas grandes cidades. Ao mesmo tempo, tal cinema seria um instrumento precioso para que cada espectador tomasse gosto pela desorientação inerente à nossa situação histórica e para que, recusando a consolação dos sentidos enlatados, aprendesse a buscar, na superfície do que aparece, os tênues vestígios de um sentido possível. A importância dessa caracterização do cinema como arte de vanguarda para a construção de Olhar e narrativa não tem como ser superestimada: além de apontar para uma possível educação estética do homem na atualidade, ela é análoga à descrição empreendida por Bernardo Oliveira do narrador moderno, que, "afetado pela nova sensorialidade urbana e pela falta de um texto herdado que facilite a decifração do mundo, percebe a urgência de ler o texto bruto e material do mundo, e sublinha de inúmeras formas o modo precário como, por um triz, consegue ainda abrir o livro do passado" (p. 88).

Com essa definição do papel do narrador moderno, o leitor chega ao terceiro e último capítulo do livro, que é uma espécie de intensificação dos anteriores, na medida em que a retomada do conceito de crítica de arte de Walter Benjamin - tema do primeiro capítulo - serve à leitura de autores contemporâneos que ele não conheceu, mas cujas obras, segundo nos revela Bernardo Oliveira, sem dúvida são afinadas com as reflexões benjaminianas sobre o privilégio do olhar na modernidade, o caráter tátil da percepção no tempo histórico que é o nosso, e o tipo de narrativa que ele exige - tema do segundo capítulo.

Ao retomar o gesto benjaminiano para ler textos publicados apenas depois da morte de Walter Benjamin, como os de Rubem Fonseca ("A arte de andar nas ruas do Rio de Janeiro"), Paul Auster ("Cidade de vidro"), Peter Handke (Lento retorno) e Chico Buarque (Benjamin, é claro!), Bernardo Oliveira escapa corajosamente aos três grandes riscos que sempre ameaçam os estudos sobre Walter Benjamin: o risco de apenas parafrasear as brilhantes interpretações benjaminianas daqueles autores de sua predileção, como Baudelaire, Proust e Kafka; o risco de confundir a reflexão estética com uma disputa escolástica sobre o significado de determinados conceitos, disputa essa que raramente serve para intensificar a fruição ou a compreensão de obras de arte específicas; 
e finalmente o risco de, no Brasil, acabarmos deixando de lado obras de autores brasileiros, que, tanto quanto as obras dos clássicos europeus e norteamericanos que costumam consumir o melhor de nossos esforços, não raro são um excelente ponto de partida para a reflexão estética e sobretudo para a discussão das múltiplas imbricações entre estética e política.

Pela originalidade na escolha das obras analisadas, a coragem e a competência com que escapa aos três perigos supramencionados, Olhar $e$ narrativa: leituras benjaminianas é um livro que merece ser lido não apenas por todos aqueles que estudam a obra de Walter Benjamin, mas também por aqueles que se interessam pelas intricadas relações entre filosofia e literatura, estética e história, arte e política. 